\title{
Sorsby pseudoinflammatory fundus dystrophy
}

INSERM

\section{Source}

INSERM. (1999). Orphanet: an online rare disease and orphan drug data base. Sorsby pseudoinflammatory fundus dystrophy. ORPHA:59181

Sorsby's fundus dystrophy is a rare progressive autosomal dominant macular dystrophy, presenting between the third and sixth decades of life, characterized by retinal atrophy and retinal detachment and leading to loss of central vision, then peripheral vision, and eventually blindness. 